\title{
Influence of Different Composites and Polishing Techniques on Periodontal Tissues near Noncarious Cervical Lesions: A Controlled, Randomized, Blinded Clinical Trial
}

\author{
Nancielli Teixeira ${ }^{1}$ Mariana Benedetti Ferreira Webber ${ }^{1}$ Carlos Augusto Nassar ${ }^{1}$ Veridiana Camilotti ${ }^{1}$ \\ Marcio José Mendonça Mario Alexandre Coelho Sinhoreti²

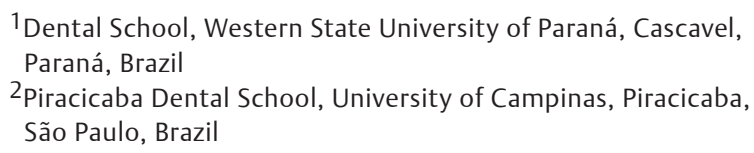

2Piracicaba Dental School, University of Campinas, Piracicaba, São Paulo, Brazil \\ Address for correspondence Marcio José Mendonça, DDS \\ MS, PhD, Department of Prosthodontics, Dental School Rua \\ Universitária, 2069-Faculdade, Cascavel-PR, Brazil, ZIP 85.819-110, \\ (e-mail: dr.mendonca@uol.com.br).
}

Eur J Dent 2019;13:635-641

\begin{abstract}
Keywords

- inflammation

- composite resins

- dental polishing

- noncarious cervical lesion
\end{abstract}

Objectives This study evaluated the long-term effect on gingival tissues near noncarious cervical lesions after restoration with different composites in association with two different polishing techniques.

Materials and Methods This study was conducted on 60 patients as a randomized, split-mouth, single-blind clinical trial and divided into four groups $(n=15)$ and restored using different composites (Tetric N-Ceram nanohibride or Z350 XT nanoparticles) and polishing materials (Astropol or Sof-Lex). The periodontal parameters analyzed were Silness-Löe plaque index; Silness-Löe gingival index; probing depth, clinical insertion level; and bleeding on probing. Periodontal analysis was performed before scaling and root planing at $30,60,120$, and 180 days after restoration.

Statistical Analysis The data submitted to the Friedman's test were employed for comparison between groups $(p<0.05)$.

Results Statistically significant differences between Z350/Astropol and other groups were observed for visible plaque and probing depth. Gingival index Tetric/Sof-Lex, the time factor did not influence the results. All experiment groups exhibited statistically significant differences in the clinical level of insertion when the follow-up time was considered. Percentage of bleeding on probing, in which there was a difference only with regard to group Tetric/Sof-Lex when the time factor was considered.

Conclusion The evaluated composites and polishing techniques did not exhibit differences in performance in the periodontal parameters analyzed at the end of 6 months of evaluation.

\section{Introduction}

Noncarious cervical lesions (NCCLs) are routinely diagnosed in dental offices and may be caused by erosion, abrasion, or occlusal stress (abfraction), which are common in clinical practice. ${ }^{1,2}$ To perform the treatment, the anatomy of the dental structure-dentin and pulp-should be considered, and the factors that trigger this condition. Several therapies are proposed for the treatment of HD, and involve protecting the dentin-pulp complex with minimally invasive and reversible techniques. ${ }^{3}$ 
Owing to advances in composite technology and the effectiveness of bonding agents, composites are being increasingly used in dentistry for the treatment of NCCLs. ${ }^{4}$ Nanoparticulate composites present load particles that promote greater surface regularity, acting as facilitators for polishing for all techniques used. ${ }^{5,6}$

Different types of materials available in the market for finishing and polishing have proven to be efficient alternatives for polishing nanoparticulate composites in in vitro studies. ${ }^{7}$ Nevertheless, in the specific case of NCCLs that are normally located at the gingival or subgingival level, the finishing and polishing step is relatively difficult, rendering these restorations more susceptible to dental biofilm accumulation, ${ }^{8}$ which could influence the color stability and biocompatibility of the restorations as well as damage to the gingival tissue. ${ }^{9}$ Since laboratory studies are limited to the possibility of extrapolating the results to the middle buccal complex, longitudinal follow-up clinical studies are necessary for a more effective evaluation of these materials and techniques. ${ }^{10}$

With the aim to streamline the finishing and polishing procedure and to improve the smoothness of restorations next to the cervical end, a two-step finishing and polishing system-in which anatomical contour, finishing, and polish procedures are performed with the same tool. It has already been mentioned that one-step systems were better or, at least, comparable to traditional multistep techniques. ${ }^{4,5}$

The aim of this study was to evaluate the long-term effect on gingival tissues near NCCLs after restoration with different composites in association with two different polishing techniques.

\section{Materials and Methods}

This blinded, prospective, randomized clinical trial was conducted between January and December 2014. The sample size was calculated based on the probability distribution of family $\mathrm{F}$, with a repeated family design and interactions within and among the factors. The effect size used was 0.15 , error type $1(\alpha)$ was 0.05 , and analysis power was 0.90 , which secured a minimum of 14 teeth per experimental group. The sample size was calculated with $\mathrm{G}^{*}$ Power software (version 3.1.9.2, University of Düsseldorf, Germany). With estimated losses during follow-up, 60 teeth were included.

The experimental design followed the Consolidated Standards of Reporting Trials (CONSORT) statement ${ }^{11}$ and was registered in the Brazilian Clinical Trials Registry (RBR7YYZNM). The study protocol was reviewed and accepted by the Local Ethics Committee on investigations involving human subjects (opinion no. 289.096). All patients, who met the selection criteria, were informed of the objectives, procedures, risks, and benefits of the study and expressed consent to participate by signing the terms of Free and Enlightened Consent.

Initially, 272 teeth of patients with NCCL-related complaints were evaluated. Among these, 60 teeth were found to be eligible ( - Fig. 1) on the basis of the following inclusion criteria: (1) adults aged 18 to 60 years; (2) NCCLs present in posterior teeth in at least two hemiarchs (split-mouth study model), with the following characteristics: from at least $1 \mathrm{~mm}$ in depth to larger lesions of approximately $5 \mathrm{~mm}$ in the occlusal-gingival direction and approximately 2 to $3 \mathrm{~mm}$ in depth; (3) absence of periodontal disease; (4) NCCL-bearing teeth having occlusal contact with the antagonist; and (5) presence of occlusal balance and absence of premature contacts. The exclusion criteria were: (1) active periodontal disease; (2) dental mobility in any degree; (3) uncontrolled caries activity; (4) xerostomia; (5) concurrent orthodontic treatment; (6) mandibular temporal dysfunction; (7) history of systemic diseases with repercussions on the gingiva and periodontal tissues; (8) history of adverse reaction to any of the materials used in this study; (9) patients with parafunctional habits; (10) use of a myorelaxant device; and (11) pregnancy or lactation. Occlusal analysis was performed in centric relation, with carbon paper to identify the contact points. Occlusal adjustments may involve altering cuspal inclines, reducing heavy contacts, and removing premature contacts. ${ }^{12}$ Patients with very inclined spits and lack of occlusal stability were not included in the study.

Based on the inclusion and exclusion criteria, selected teeth were then divided into four groups by means of the block randomization $(15 \times 4),(n=15$; - Fig. 1). Because this was a split-mouth study, each patient received a different treatment in each hemiarch such that the variation adopted for each patient was the polishing system; that is, each patient received the treatment for their NCCL with the same composite, albeit with different polishing systems. The materials used for restoration in this study are described in - Table 1. The restorations were made by a single trained operator, and the longitudinal evaluation of the restorations was performed independently by another trained evaluator.

The initial clinical examination was performed by a single, previously trained examiner, different from other operators. The clinical examination, performed with the aid of a Williams-type periodontal probe number 23, determined the following parameters: (1) Silness-Löe plaque index ${ }^{13}$; (2) Silness-Löe gingival index ${ }^{14}$; (3) probing depth; (4) clinical insertion level; and (5) bleeding on probing. The same procedure was used at each longitudinal evaluation at 30, 60, 120, and 180 days after restoration and polishing.

After the initial clinical examination, all patients were administered basic periodontal therapy, with scaling and root planing of all teeth in the buccal cavity, following which they received the necessary restorations on the NCCLinvolved teeth. All groups of patients received guidance for the mechanical control of oral hygiene using the modified Bass brushing technique at all time points of the study.

The lesions were restored using total acid conditioning technique in accordance with the manufacturers' instructions. After 7 days, the restorations were finished and polished using either one of the polishing techniques, depending on the experimental group. For the groups that were designated to receive polishing with the Astropol rubber tips, the process was started with the gray tip which was followed by the green and pink tips (for 10 seconds each). For the groups 


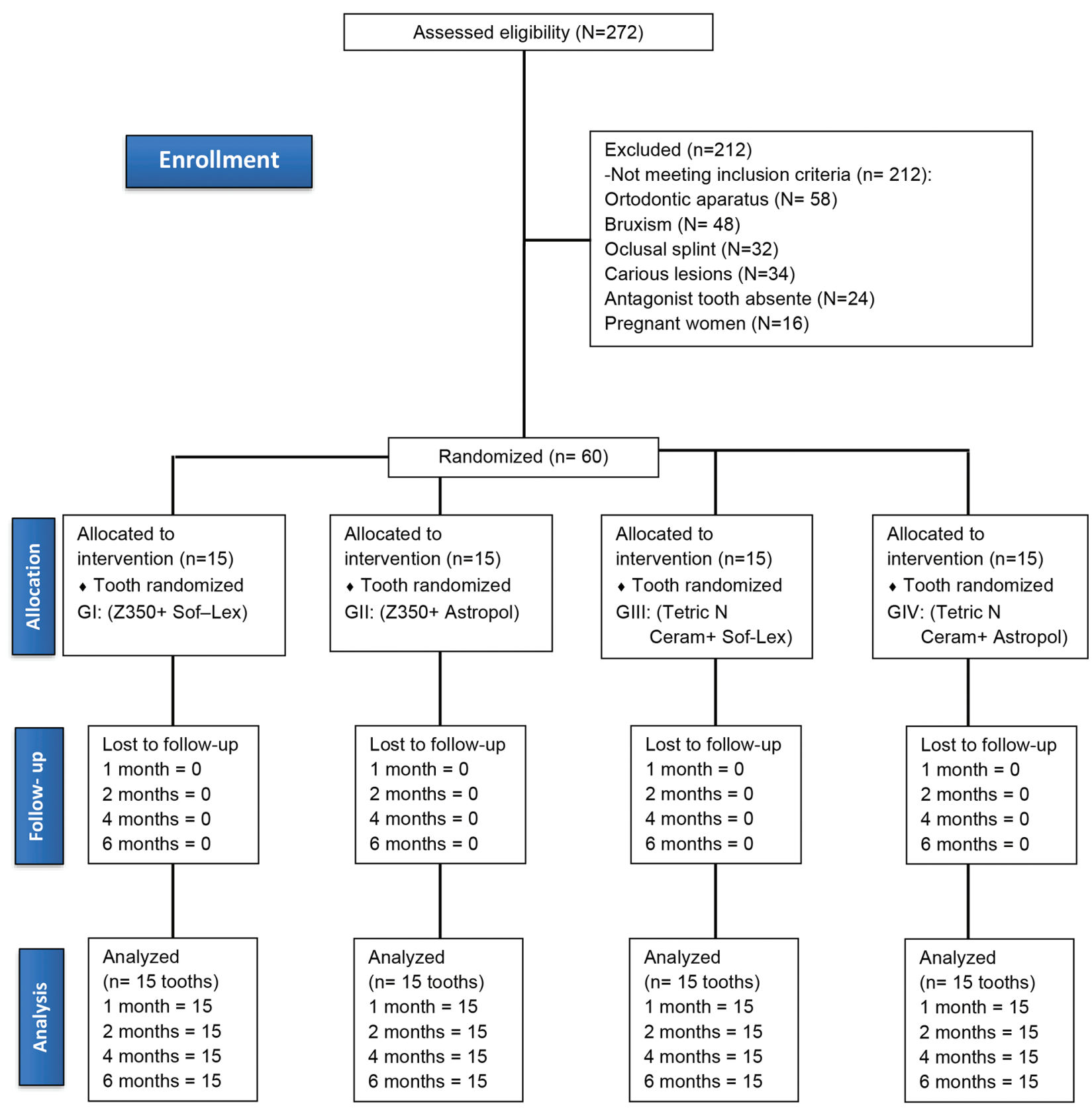

Fig. 1 CONSORT flow diagram of the clinical trial. CONSORT, Consolidated Standards of Reporting Trials.

that were designated to receive polishing with the Sof-Lex Pop-On blue discs, polishing was started with the medium disc, followed by the thin and extra-thin discs (for 10 seconds each). At each series replacement, the restorations were washed for 10 seconds using an air/water jet to remove the polishing residue, dried using an air jet for 10 seconds, and polished using a thinner disc/rubber tip. The discs and rubber tips were replaced with new ones after being used for polishing two restorations.

The data obtained were initially submitted to the Shapiro-Wilk test, with negative results for normality. The data were then submitted to the Friedman test, with a significance level of 5\% (BioEstat 5.1; Instituto Mamirauá, Amazonas, Brazil).

\section{Results}

The volunteers included in this study had a mean age of 38.7 years (age range, $30-48$ years; male, $14 \%$; female, $86 \%$ ). The results obtained for each of the variables evaluated in the experimental groups are described in $\boldsymbol{- T a b l e s} \mathbf{2}$ to $\mathbf{6}$.

- Table 2 shows the results of analysis of the plaque index in each of the experimental groups. For groups Z350/Sof-Lex, Tetric/Sof-Lex, and Tetric/Astropol, the differences in the plaque index were found to be statistically significant when only the follow-up time was considered; in contrast for group Z350/Astropol, the time factor did not influence the results. Upon intergroup comparison of plaque indices, statistically significant differences were observed in the initial period 
Table 1 Commercial brands, composition, and batch numbers of the composites used in the experimental groups

\begin{tabular}{|c|c|c|c|}
\hline Materials & Composition & Manufacturer & Batch \\
\hline Filtek Z350 & $\begin{array}{l}\text { Organic matrix: BisGMA, BisEMA } \\
\text { Inorganic matrix: Zirconia-silica, } 0.6-1.4 \mu \mathrm{m} \text {; nanoparticles of } \\
\mathrm{SiO}_{2}, 20 \mathrm{~nm}\end{array}$ & $\begin{array}{l}\text { 3M ESPE, Sumaré, } \\
\text { SP, Brazil }\end{array}$ & $\begin{array}{l}881382 \\
944038\end{array}$ \\
\hline Tetric N-Ceram & $\begin{array}{l}\text { Urethane dimethacrylate, Bis-GMA, 15\%; } \\
\text { ethoxylated Bis-EMA, } 3.8 \% \text {; } \\
\text { barium glass, ytterbium trifluoride, } \\
\text { mixed oxide, silicon dioxide, } \\
63.5 \% \text {; prepolymers, } 17 \% \text {; } \\
\text { additives, stabilizers, catalysts, } \\
\text { pigments, } 0.7 \%\end{array}$ & $\begin{array}{l}\text { IvoclarVivadent, } \\
\text { Barueri, SP, Brazil }\end{array}$ & $\begin{array}{l}\text { S24101 } \\
\text { T08031 }\end{array}$ \\
\hline Single Bond Universal & $\begin{array}{l}\text { BisGMA, HEMA, } \\
\text { dimethacrylates, ethanol, water, an innovative photoinitiator } \\
\text { system, and a functional copolymer of } \\
\text { polyacrylic and polyalkanoic acid methacrylate }\end{array}$ & $\begin{array}{l}\text { 3M ESPE, Sumaré, } \\
\text { SP, Brazil }\end{array}$ & 509806 \\
\hline Sof-Lex & Aluminum discs with medium, thin, and extra-thin particle size & $\begin{array}{l}\text { 3M ESPE, Sumaré, } \\
\text { SP, Brazil }\end{array}$ & $\begin{array}{l}\text { N1207991208800037 } \\
1208800038\end{array}$ \\
\hline Astropol & $\begin{array}{l}\text { F (gray) and P (green): silicon rubber tip, silicon carbide particles, } \\
\text { and colored pigments. } \\
\text { HP (pink): silicone rubber, diamond particles, aluminum oxide, } \\
\text { titanium oxide, and iron oxide }\end{array}$ & $\begin{array}{l}\text { Ivoclar Vivadent, } \\
\text { Barueri, SP, Brazil }\end{array}$ & 004122 \\
\hline
\end{tabular}

Table 2 Plaque indices (\%) observed in the experimental groups according to time

\begin{tabular}{|l|l|l|l|l|l|}
\hline Groups & Initial & 30 days & 60 days & 120 days & 180 days \\
\hline Z350/Sof-Lex & $54 \pm 0.20 \mathrm{Aa}$ & $40 \pm 0.24 \mathrm{Aab}$ & $24 \pm 0.15 \mathrm{Abc}$ & $18 \pm 0.15 \mathrm{Ac}$ & $10 \pm 0.15 \mathrm{Ac}$ \\
\hline Z350/Astropol & $28 \pm 0.13 \mathrm{Ba}$ & $28 \pm 0.13 \mathrm{Aa}$ & $21 \pm 0.06 \mathrm{Aa}$ & $15 \pm 0.10 \mathrm{Aa}$ & $15 \pm 0.10 \mathrm{Aa}$ \\
\hline Tetric/Sof-Lex & $42 \pm 0.15 \mathrm{Aba}$ & $33 \pm 0.16 \mathrm{Aa}$ & $25 \pm 0.10 \mathrm{Aab}$ & $17 \pm 0.08 \mathrm{Ab}$ & $17 \pm 0.08 \mathrm{Ab}$ \\
\hline Tetric/Astropol & $53 \pm 0.26 \mathrm{Aba}$ & $26 \pm 0.12 \mathrm{Aab}$ & $26 \pm 0.18 \mathrm{Aab}$ & $26 \pm 0.13 \mathrm{Aab}$ & $21 \pm 0.12 \mathrm{Ab}$ \\
\hline
\end{tabular}

Note: Data are shown as mean values \pm standard deviation. Different letters in the same row or column indicate statistically significant differences $(p<0.5)$. Uppercase letters for columns and lowercase letters for rows.

Table 3 Gingival indices (\%) observed in the experimental groups according to time

\begin{tabular}{|l|l|l|l|l|l|}
\hline Groups & Initial & $\mathbf{3 0}$ days & 60 days & 120 days & 180 days \\
\hline Z350/Sof-Lex & $16 \pm 0.07 \mathrm{Aa}$ & $10 \pm 0.05 \mathrm{Aab}$ & $8 \pm 0.04 \mathrm{Ab}$ & $7 \pm 0.04 \mathrm{Ab}$ & $7 \pm 0.04 \mathrm{Ab}$ \\
\hline Z350/Astropol & $17 \pm 0.10 \mathrm{Aa}$ & $12 \pm 0.08 \mathrm{Aab}$ & $10 \pm 0.04 \mathrm{Aab}$ & $6 \pm 0.04 \mathrm{Ab}$ & $6 \pm 0.04 \mathrm{Ab}$ \\
\hline Tetric/Sof-Lex & $12 \pm 0.07 \mathrm{Aa}$ & $8 \pm 0.04 \mathrm{Aa}$ & $7 \pm 0.04 \mathrm{Aa}$ & $7 \pm 0.04 \mathrm{Aa}$ & $7 \pm 0.04 \mathrm{Aa}$ \\
\hline Tetric/Astropol & $15 \pm 0.08 \mathrm{Aa}$ & $8 \pm 0.06 \mathrm{Aab}$ & $7 \pm 0.04 \mathrm{Ab}$ & $7 \pm 0.04 \mathrm{Ab}$ & $7 \pm 0.03 \mathrm{Ab}$ \\
\hline
\end{tabular}

Note: Data are shown as mean values \pm standard deviation. Different letters in the same row or column indicate statistically significant differences $(p<0.5)$. Uppercase letters for columns and lowercase letters for rows.

between groups Z350/Sof-Lex and Z350/Astropol. There were no significant intergroup differences in the plaque index at other time points, and the composites and polishes were considered to provide similar results.

- Table 3 shows the results of analysis of the gingival index in each experimental group. For groups Z350/Sof-Lex, Z350/ Astropol, and Tetric/Astropol, the differences in gingival index were statistically significant when only the follow-up time was considered; in contrast, for group Tetric/Sof-Lex, the time factor did not influence the results. In addition, the results of intergroup comparison did not reveal any statistically significant differences in the gingival index among the groups.

- Table 4 shows the results obtained upon analysis of the probing depth in each experimental group. For groups Z350/ Sof-Lex, Tetric/Sof-Lex, and Tetric/Astropol, the differences in probing depth were statistically significant when the follow-up time was considered; in contrast, for group Z350/ Astropol, the time factor did not influence the results. Upon intergroup comparison of probing depth, it was observed that groups Z350/Sof-Lex and Z350/Astropol differed significantly from groups Tetric/Sof-Lex and Tetric/Astropol at the initial time point and at 60 days. At 30 and 120 days, groups Z350/Sof-Lex, Z350/Astropol, and Tetric/Sof-Lex differed significantly from group Tetric/Astropol. At 180 days, there were no statistically significant differences in probing depth among the groups; after 6 months, the composites and the polishes were equalized and all were well tolerated by the gingival tissues.

- Table 5 shows the results of the analysis of the clinical level of insertion in each of the experimental groups. All experiments groups exhibited statistically significant differences in the clinical level of insertion when the follow-up 
Table 4 Probing depth ( $\mathrm{mm}$ ) observed in the experimental groups according to time

\begin{tabular}{|l|l|l|l|l|l|}
\hline Groups & Initial & 30 days & 60 days & 120 days & 180 days \\
\hline Z350/Sof-Lex & $1.77 \pm 0.43 \mathrm{Aa}$ & $1.71 \pm 0.49 \mathrm{Aab}$ & $1.67 \pm 0.40 \mathrm{Aab}$ & $1.57 \pm 0.40 \mathrm{Aab}$ & $1.57 \pm 0.40 \mathrm{Ab}$ \\
\hline Z350/Astropol & $1.70 \pm 0.28 \mathrm{Aa}$ & $1.60 \pm 0.29 \mathrm{Aa}$ & $1.56 \pm 0.25 \mathrm{ACa}$ & $1.48 \pm 0.28 \mathrm{Aba}$ & $1.49 \pm 0.29 \mathrm{Aa}$ \\
\hline Tetric/Sof-Lex & $2.17 \pm 0.23 \mathrm{Ba}$ & $1.94 \pm 0.27 \mathrm{ABab}$ & $1.89 \pm 0.23 \mathrm{Bab}$ & $1.83 \pm 0.26 \mathrm{ABb}$ & $1.80 \pm 0.24 \mathrm{Ab}$ \\
\hline Tetric/Astropol & $1.74 \pm 0.26 \mathrm{Ba}$ & $1.66 \pm 0.25 \mathrm{Bac}$ & $1.60 \pm 0.20 \mathrm{Bbc}$ & $1.45 \pm 0.31 \mathrm{Bb}$ & $1.45 \pm 0.31 \mathrm{Ab}$ \\
\hline
\end{tabular}

Note: Data are shown as mean values \pm standard deviation. Different letters in the same row or column indicate statistically significant differences $(p<0.5)$. Uppercase letters for columns and lowercase letters for rows.

Table 5 Clinical insertion level ( $\mathrm{mm}$ ) observed in the experimental groups according to time

\begin{tabular}{|l|l|l|l|l|l|}
\hline Groups & Initial & 30 days & 60 days & 120 days & 180 days \\
\hline Z350/Sof-Lex & $1.77 \pm 0.43 \mathrm{ABa}$ & $1.71 \pm 0.49 \mathrm{Aab}$ & $1.67 \pm 0.40 \mathrm{ABab}$ & $1.57 \pm 0.40 \mathrm{ABb}$ & $1.57 \pm 0.40 \mathrm{Ab}$ \\
\hline Z350/Astropol & $1.70 \pm 0.28 \mathrm{Aa}$ & $1.60 \pm 0.29 \mathrm{Aad}$ & $1.56 \pm 0.25 \mathrm{Abd}$ & $1.48 \pm 0.28 \mathrm{Abc}$ & $1.49 \pm 0.29 \mathrm{Ac}$ \\
\hline Tetric/Sof-Lex & $2.17 \pm 0.23 \mathrm{ABa}$ & $1.94 \pm 0.27 \mathrm{Aab}$ & $1.89 \pm 0.23 \mathrm{Abc}$ & $1.83 \pm 0.26 \mathrm{Bbc}$ & $1.80 \pm 0.24 \mathrm{Ac}$ \\
\hline Tetric/Astropol & $2.18 \pm 0.31 \mathrm{Ba}$ & $1.95 \pm 0.29 \mathrm{Aab}$ & $1.90 \pm 0.26 \mathrm{Bbc}$ & $1.83 \pm 0.24 \mathrm{ABbc}$ & $1.82 \pm 0.24 \mathrm{Ac}$ \\
\hline
\end{tabular}

Note: Data are shown as mean values \pm standard deviation. Different letters in the same row or column indicate statistically significant differences $(p<0.5)$. Uppercase letters for columns and lowercase letters for rows.

Table 6 Percentage of bleeding on probing in the experimental groups according to time

\begin{tabular}{|l|l|l|l|l|l|}
\hline Groups & Initial & 30 days & 60 days & 120 days & 180 days \\
\hline Z350/Sof-Lex & $10 \pm 0.07 \mathrm{Aa}$ & $10 \pm 0.06 \mathrm{Aa}$ & $8 \pm 0.03 \mathrm{Aa}$ & $8 \pm 0.04 \mathrm{Aa}$ & $8 \pm 0.04 \mathrm{Aa}$ \\
\hline Z350/Astropol & $8 \pm 0.05 \mathrm{Aa}$ & $8 \pm 0.04 \mathrm{Aa}$ & $8 \pm 0.03 \mathrm{Aa}$ & $8 \pm 0.04 \mathrm{Aa}$ & $8 \pm 0.04 \mathrm{Aa}$ \\
\hline Tetric/Sof-Lex & $7 \pm 0.04 \mathrm{Aa}$ & $8 \pm 0.05 \mathrm{Aa}$ & $9 \pm 0.04 \mathrm{Aa}$ & $8 \pm 0.06 \mathrm{Aa}$ & $8 \pm 0.05 \mathrm{Aa}$ \\
\hline Tetric/Astropol & $11 \pm 0.06 \mathrm{Aa}$ & $8 \pm 0.04 \mathrm{Aab}$ & $8 \pm 0.03 \mathrm{Aab}$ & $5 \pm 0.04 \mathrm{Ab}$ & $5 \pm 0.04 \mathrm{Ab}$ \\
\hline
\end{tabular}

Note: Data are shown as mean values \pm standard deviation. Different letters in the same row or column indicate statistically significant differences $(p<0.5)$. Uppercase letters for columns and lowercase letters for rows.

time was considered. The results of intergroup comparison of the clinical level of insertion revealed statistically significant differences among the groups. At 30 and 180 days, all four experimental groups exhibited similar results. At the initial time point and at 60 and 120 days, group Z350/Sof-Lex exhibited results similar to those of the other groups, while at the initial time point and at 60 days, the group Z350/Astropol exhibited differences relative to the group Tetric/Astropol.

- Table 6 shows the results of analysis of the percentage of bleeding on probing, in which there was a difference only with regard to group Tetric/Sof-Lex when the time factor was considered. The other groups, when compared simultaneously, did not present significant differences, irrespective of the time of evaluation.

\section{Discussion}

The use of composites and suitable finishing and polishing systems provides a reduction in bacterial biofilm retention and minimizes the possibility of gingival inflammation, thereby preventing the development of periodontal diseases around the NCCLs. ${ }^{15-18}$ Additionally, the sum of all these factors also increases the survival duration of these restorations, thus reducing the chances of development of caries on the surface of these lesions when exposed and also minimizing the risk of secondary caries. Thus, composites and polishing systems can be considered to be compatible with periodontal tissues. ${ }^{9}$

In the present periodontal analysis, it was possible to observe significant differences in plaque index and probing depth in groups Z350/Sof-Lex, Tetric/Sof-Lex, and Tetric/Astropol when only time was considered. The results revealed a substantial decrease in the plaque index in these three groups after preparation of the restorations and completion of the corresponding polishing processes. The decrease observed in these indices confirms that guidance and motivation regarding oral hygiene, coupled with the preparation of adequately polished restorations, may contribute to the prevention of periodontal diseases, thereby reducing the accumulation of biofilm between the teeth and periodontal tissues..$^{15}$ In contrast, no significant differences were observed with regard to plaque index or probing depth in group Z350/Astropol. The major limitation of this study was some groups presented differences in the parameters evaluated at the initial evaluation. Sapra et $\mathrm{al}^{15}$ observed in a laboratory study that the surface roughness of the Z350 composite is lower with the increase in the number of steps of the polishing technique. Decreasing the plaque index with time of assessment may improve patient hygiene and/or changes in eating habits.

Regarding the gingival index, it was verified that in groups, Z350/Soft-Lex, Z350/Astropol, and Tetric/Astropol, 
the index decreased with time with statistically significant differences. In Tetric/Soft-Lex, however, the time factor did not statistically influence the results. Similar results were found by Hassan et $\mathrm{al}^{19}$ in a laboratory study, they mentioned that Sof-Lex system resulted in rougher surfaces. This disagreement may be due to the use of different types of resin composite than those used in our study. Astropol HP contains diamond particles in its composition, while Sof-Lex discs use aluminum oxide as abrasive particles. Diamond is harder than aluminum, causing deeper grooves on the surface of the composite, which results in more roughness. ${ }^{20}$ In case of the clinical insertion index, the results of individual analysis of the experimental groups while considering the time factor revealed a statistically significant decrease in this index in all of the groups. The clinical insertion index represents the current gold standard in periodontal diagnosis, and the improvement of this parameter in all groups in the present study shows that the treatment was well tolerated by the periodontal tissues, leading to the improvement in gingival indices.

In case of the gingival bleeding index, Teric/Astropol exhibited statistically significant differences in this parameter when only time was considered. In agreement with these results, Nassar et $\mathrm{al}^{21}$ observed a reduction in all these periodontal indices after composite restoration of NCCLs using the Z350 XT composite, with variations in performance among the Sof-Lex, Astropol PoGo (Dentsply, Petrópolis, Brazil), and FLEXI CUPS (Cosmedent Corp., Chicago, IL, United States) rubber polishing systems after a period of 120 days. These authors ${ }^{21}$ also provided guidance and motivation on oral hygiene for their patients by means of periodontal support therapy both at the beginning and during the course of treatment. Al-Qutub ${ }^{22}$ observed that oral hygiene guidance-through teaching adequate brushing techniques and providing motivation for brushing-helps to improve gingival inflammation rates and gingival crevicular fluid volumes.

McCoy et al, ${ }^{23}$ in a 3-year follow-up clinical study, observed that the use of composites for the treatment of NCCLs does not cause damage to the periodontal tissues. In this study, the authors evaluated the effect of composites under periodontal tissues through analysis of the probing depth and bleeding on probing indices.

There are different adhesion protocols that can be used for NCCLs restorations such as conventional (CA) using total acid etching, self-etching (SE) that does not require prior acid etching and universal that can be used both as conventional and SE. There is insufficient evidence to support one adherence protocol over another when comparing the efficacy of adhesives for the treatment of NCCLs. Yaman et al, ${ }^{24}$ in a prospective 3-year follow-up clinical study, found no significant differences in CA or SE restored NCCLs. Al-Agha and Alagha ${ }^{25}$ evaluated marginal nanoinfiltration of CA and SE-restored class $\mathrm{V}$ restorations and reported greater marginal nanoinfiltration for SE-restored cavities. Peumans et $\mathrm{al}^{26}$ after 9 years of clinical service, class-V restorations bonded with the CA performed clinically equally successful as those bonded with the SE. However, more marginal deterioration, though still clinically acceptable, was recorded at the incisal enamel side for the SE. So, the etching and rinsing technique was selected as the most effective approach to achieve efficient and stable bonding to enamel and dentin. ${ }^{27}$

The clinical observation of the present results, along with the observed changes in periodontal indices, leads us to consider that there was a decrease in the inflammation levels of the tissues adjacent to the restored teeth. Thus, the present results suggest that NCCL treatment with composites and adequate finishing and polishing techniques showed good biocompatibility for the periodontal tissues even after 180 days-with no evidence of irritation or inflammation in these tissues-which ensured that they remained in good health. Additionally, this study was able to show that the different composites and finishing systems evaluated here did not influence the accomplishment of different outcomes for periodontal variables.

\section{Conclusion}

On the basis of the methodology and results of this study, it can be concluded that the evaluated composites and polishing techniques did not exhibit differences in performance of the periodontal parameters analyzed at the end of 6 months of evaluation of different combinations of composites and polishing systems.

\section{Conflict of Interest}

None declared.

\section{Acknowledgment}

We thank Coordenadoria de Aperfeiçoamento de Pessoal de Nível Superior (CAPES; Brasília, Brazil) for providing financial support.

\section{References}

1 Levitch LC, Bader JD, Shugars DA, Heymann HO. Non-carious cervical lesions. J Dent 1994;22(4):195-207

2 Van Meerbeek B, De Munck J, Yoshida Y, et al. Buonocore memorial lecture. Adhesion to enamel and dentin: current status and future challenges. Oper Dent 2003;28(3):215-235

3 Browning WD, Dennison JB. A survey of failure modes in composite resin restorations. Oper Dent 1996;21(4):160-166

4 Bashetty K, Joshi S. The effect of one-step and multi-step polishing systems on surface texture of two different resin composites. J Conserv Dent 2010;13(1):34-38

5 Senawongse P, Pongprueksa P. Surface roughness of nanofill and nanohybrid resin composites after polishing and brushing. J Esthet Restor Dent 2007;19(5):265-273,

6 de Moraes RR, Gonçalves LdeS, Lancellotti AC, Consani S, Correr-Sobrinho L, Sinhoreti MA. Nanohybrid resin composites: nanofiller loaded materials or traditional microhybrid resins? Oper Dent 2009;34(5):551-557

7 Sapra V, Taneja S, Kumar M. Surface geometry of various nanofiller composites using different polishing systems: a comparative study. J Conserv Dent 2013;16(6):559-563

8 Rosin M, Steffen H, Konschake C, et al. One-year evaluation of an Ormocer restorative-a multipractice clinical trial. Clin Oral Investig 2003;7(1):20-26

9 Santerre JP, Shajii L, Leung BW. Relation of dental composite formulations to their degradation and the release of hydrolyzed polymeric-resin-derived products. Crit Rev Oral Biol Med 2001;12(2):136-151 
10 Dutra D, Pereira G, Kantorski KZ, Valandro LF, Zanatta FB. Does finishing and polishing of restorative materials affect bacterial adhesion and biofilm formation? A systematic review. Oper Dent 2018;43(1):E37-E52

11 Schulz KF, Altman DG, Moher D; CONSORT Group. CONSORT 2010 statement: updated guidelines for reporting parallel group randomised trials. BMJ 2010;340:c332 10.1136/bmj.c332

12 Michael JA, Townsend GC, Greenwood LF, Kaidonis JA. Abfraction: separating fact from fiction. Aust Dent J 2009;54(1):2-8

13 Silness J, Loe H. Periodontal disease in pregnancy. II. correlation between oral hygiene and periodontal condition. Acta Odontol Scand 1964;22:121-135

14 Loe $\mathrm{H}$, Silness J. Periodontal disease in pregnancy. I. Prevalence and severity. Acta Odontol Scand 1963;21:533-551

15 dos Santos GG, Rego DM. The influence of a gummy smile on lip seal. J Int Acad Periodontol 2007;9(2):53-57

16 Gurgel BC, Solera NG, Peixoto RF, Assis AO, Calderon PD, Medeiros MC. Evaluation of the periodontal conditions of teeth with restored and non-restored non-carious cervical lesions. Quintessence Int 2016;47(10):825-831

17 Cazzaniga G, Ottobelli M, Ionescu AC, et al. In vitro biofilm formation on resin-based composites after different finishing and polishing procedures. J Dent 2017;67:43-52

18 Berger SB, Palialol AR, Cavalli V, Giannini M. Surface roughness and staining susceptibility of composite resins after finishing and polishing. J Esthet Restor Dent 2011;23(1):34-43

19 Hassan AM, Nabih SM, Mossa HM, Baroudi K. The effect of three polishing systems on surface roughness of flowable, microhybrid, and packable resin composites. J Int Soc Prev Community Dent 2015;5(3):242-247
20 Lins FC, Ferreira RC, Silveira RR, Pereira CN, Moreira AN, Magalhães CS. Surface roughness, microhardness, and microleakage of a silorane-based composite resin after immediate or delayed finishing/polishing. Int J Dent 2016;2016:8346782

21 Nassar CA, Nassar PO, Secundes MB, Busato PdoM, Camilotti V. Composite resin restorations of non-carious cervical lesions in patients with diabetes mellitus and periodontal disease: pilot study. Acta Odontol Latinoam 2012;25(3):279-286

22 Al-Qutub. Gingival crevicular fluid and oral hygiene in Saudi dental students and interns. Pakistan Oral \& Dental Journal. 2009;29:337-340

23 McCoy RB, Anderson MH, Lepe X, Johnson GH. Clinical success of class $\mathrm{V}$ composite resin restorations without mechanical retention. J Am Dent Assoc 1998;129(5):593-599

24 Yaman BC, Doğruer I, Gümüştaş B, Efes BG. Three-year randomized clinical evaluation of a low-shrinkage silorane-based resin composite in non-carious cervical lesions. Clin Oral Investig 2014;18(4):1071-1079

25 Al-Agha EI, Alagha MI. Nanoleakage of class V resin restorations using two nanofilled adhesive systems. J Int Oral Health 2015;7(7):6-11

26 Peumans M, Wouters L, De Munck J, Van Meerbeek B, Van Landuyt K. Nine-year clinical performance of a HEMA-free one-step self-etch adhesive in noncarious cervical lesions. J Adhes Dent 2018;20(3):195-203

27 Peumans M, Kanumilli P, De Munck J, Van Landuyt K, Lambrechts P, Van Meerbeek B. Clinical effectiveness of contemporary adhesives: a systematic review of current clinical trials. Dent Mater 2005;21(9):864-881 